\title{
Reflexões acerca do Educandário Nogueira de Faria e Bioética: agenciamento de menores na Illha de Cotijuba-Pará no início do século XX
}

\author{
Atriana Elisa de Alencar Macedo * \\ Liliane da filva frança Corrêa **
}

\section{RESUMO}

Este artigo é resultado de uma investigação em percurso de doutoramento pela Universidade Federal do Pará no programa de Pós-Graduação em Psicologia. Serão analisados os agenciamentos das práticas no Educandário Nogueira de Faria na ilha de Cotijuba no início do século $X X$, relacionado ao conceito contemporâneo de bioética. Para isso, a análise principal será focada em trechos das três entrevistas realizadas com dois ex-funcionários que possuíram uma relação direta com os menores que por ali passaram e que agenciaram o funcionamento do Educandário e um exeducando, contribuindo para uma reflexão sobre a história da infância abandonada e desvalida na Amazônia paraense em interface com a bioética, em uma época que vigorava a primeira República, na qual,

\footnotetext{
*Mestra em Psicologia pelo Programa de Pós-Graduação em Psicologia (PPGP/IFCH/UFPA). Belém/Pará/Brasil. Bolsista do programa de doutorado-sanduíche no exterior (PDSE edital n¹9/2016) - Universidade de Évora. Processo n88881.134010/2016-01.E-mail: drica macedo@ yahoo.com.br

** Mestra em Educação pelo Programa de Pós-Graduação em Educação da Universidade Federal do Pará (PPGED/ICED/UFPA). Belém/Pará/Brasil. E-mail: lilafrcs@yahoo.com.br.
}

@rquivo Brasileiro de Educação, Belo Horizonte, v. 6, n. 14, mai-ago, 2018. 
as discussões sobre a institucionalização da infância no Brasil estava em seu auge.

Palavras-chave: Educandário Nogueira de Faria. Bioética. Institucionalização. Infância.

\section{ABSTRACT}

This paper is the result of an investigation in course of a doctorate period by the Federal University of Pará in the Post-graduation Program in Psychology. We will analyze the recruiting practices in the Nogueira de Faria School in the Cotijuba Island in the beginning of the $20^{\text {th }}$ century, related to the contemporary concept of bioethics. In order to do it, the main analysis will be focused in parts of three interviews carried out with two ex-employees that had direct contacts with the minors that attended there and that supported the school, and an ex-student, contributing for a reflection about the history of the abandoned and helpless childhood in the Amazon, more specifically in the state of Pará, together with the bioethics, during a period that the first Republic was ruling, in which the discussions about the institutionalization of the childhood in Brazil was in its peak.

Key-words: Nogueira de Faria School. Institutionalization. Childhood.

\section{Políticas de assistência à infância}

Falar sobre as políticas de assistência a infância abandonada e delinquente é algo complexo, uma vez que, está intimamente ligada a vários atravessamentos éticos e sociais. Essas políticas, em geral, culminavam na institucionalização desses menores', sobretudo no início do século XX.

\footnotetext{
${ }^{1}$ Todo sujeito menor de 18 anos.
}

@rquivo Brasileiro de Educação, Belo Horizonte, v. 6, n. 14, mai-ago, 2018. 
As primeiras décadas deste século foram marcadas por grandes mudanças, como por exemplo, o rompimento da invisibilidade da infância, principalmente da infância abandonada e desvalida.

\begin{abstract}
A ideia de infância não existiu sempre, e nem da mesma maneira. Ao contrário, ela aparece com a sociedade capitalista, urbano industrial, na medida em que mudam a inserção e o papel social da criança na comunidade. Se, na sociedade feudal, a criança exercia um papel produtivo direto ("de adulto") assim que ultrapassava o período de alta mortalidade infantil, na sociedade burguesa ela passa a ser alguém que precisa ser cuidada, escolarizada e preparada para uma atuação futura. Este conceito de infância é, pois, determinado historicamente pela modificação das formas de organização da sociedade. (KRAMER, 2001, p.19).
\end{abstract}

Neste contexto, a Amazônia vivenciava-se o período de ouro do látex, o que proporcionou na capital paraense, transformações econômicas e políticas. A produção da borracha despertou um grande interesse mundial voltado para a região, pois era a única capaz de produzir naturalmente esta matéria prima. É possível observar este contexto na citação abaixo.

[...] O crescimento do Pará, de 16.000 em 1850, para seja lá o que for hoje - 130.000 ou 185.000 - é unicamente devido ao crescimento do comércio da borracha. Todas as demais fontes de riqueza são insignificantes ao lado desse principal produto da indústria amazônica. Os primeiros registros que encontrei sobre a exportação de borracha do Amazonas datam de 1830, quando uma quantia de 156 toneladas foi transportada do Pará. O comércio havia mais do que duplicado em 1840 quando 388 toneladas foram transportadas e, em 1850 esse número havia aumentado para 1.467 toneladas. (MITCHELL, 2011, p. 69).

Um período que possibilitou a produção de uma grande riqueza, porém nas mãos de poucos e estes poucos, vivenciaram neste momento o glamourEuropeu. A grande produção da borracha povoou - imaginário social nacional coadunando com a política de colonização, gerou um grande movimento de migração de mão de

@rquivo Brasileiro de Educação, Belo Horizonte, v. 6, n. 14, mai-ago, 2018. 
obra para trabalhar nos seringais a procura de prosperidade econômica.

Com efeito, desta grande migração desordenada, sem mínima estrutura de saúde e educação, saneamento básico e planejamento populacional, foi inevitável a expansão de doenças, no meio deste grande conglomerado.

Nessa perspectiva, os mais afetados eram os filhos dos trabalhadores, com a alta da mortalidade infantil-juvenil e aquisição de doenças tropicais. Como propõem a Guillem:

Apesar disso, quando do recrutamento dos "soldados" para a Amazônia, criou-se a ilusão de que se tratava de um programa geral de colonização de um território "vazio" com garantias e proteção do Estado, e não de providenciar mão-de-obra barata para a elite agrária amazônica (GUILLEN, 2002, p. 6982).

O auge do extrativismo dos seringais e da produção da borracha na Amazônia foi uma época de amplos paradoxos, pois ao mesmo tempo trouxe riqueza e pobreza, desenvolvimento e retrocessos. Como nos diz Mitchell nas citações abaixo:

P Pará estava desfrutando do auge de seu desenvolvimento.
As avenidas graciosas eram alinhadas por mangueiras que
sombreavam o vasto sistema de transporte público e, sob o
governo estatal do Dr. Augusto Montenegro, foi realizado um
extenso trabalho de aperfeiçoamento cívico, o que tornou a
cidade a metrópole tropical mais moderna do mundo.
(MITCHELL, 2011, p.30).

Ele chamou a atenção para o nível desproporcional de lucros acumulados pelo governo federal no Brasil, a partir dos interesses econômicos do país na Amazônia e para o pouco que foi investido de volta na região a fim de melhorar a saúde, a educação e o bem-estar social. (MITCHELL, 2011, p.31).

A Amazônia exportava toneladas de borracha, o que a tornava alvo de grandes interesses. Esta época ficou conhecida como a "belle é poque"ou a era de "ouro da borracha".

@rquivo Brasileiro de Educação, Belo Horizonte, v. 6, n. 14, mai-ago, 2018. 
Após anos em seu auge, houve dois episódios que colaboraram para o seu declínio. A primeira ligada ao furto das sementes das seringueiras e a segunda ligada à falta de condições de prover a demanda mundial da borracha, que aumentou consideravelmente no início do século XX.

Segundo uma entrevista dada ao jornal gazeta do povo, a historiadora Maria Verónica Secreto afirmou que:

\begin{abstract}
Sob o pretexto de buscar penas de cores vibrantes para chapéus femininos das inglesas da Era Vitoriana, o inglês Henry Wickham desembarcou em fins do século XIX no coração da Floresta Amazônica com outro plano em mente: furtar sementes de seringueira, enroladas em folhas de banana, para serem entregues ao Jardim Botânico Real da Inglaterra. Foi assim que a árvore nativa da Amazônia foi retirada de seu hábitat natural e, apesar das especulações de que não resistiria em outros climas, algumas sementes (cerca de 2,7 mil das 70 mil furtadas) germinaram e foram enviadas à colônias da Inglaterra, como a Malásia, Cingapura e Ceilão. [...] A produção da borracha nas colônias inglesas era mais organizada, afinal as seringueiras foram plantadas enfileiradas, uma monocultura, bem diferente do Brasil, onde as seringueiras estão espalhadas pela floresta. Nas colônias, localizadas na Ásia, a plantação deu certo porque lá não havia - e não há até hoje - uma praga de fungos ou insetos que mata as seringueiras. No Brasil, plantar as seringueiras em fileiras seria inviável pelo risco de se perder todo o investimento de uma hora para outra. [...] A produção de látex na Amazônia depende de trabalhadores que caminhem grandes extensões dentro da mata até as seringueiras. É muito mais sofrido do que na monocultura, explica. O modelo de trabalho também era fracassado. Os trabalhadores começavam endividados, porque tinham de pagar pelos próprios instrumentos de trabalho, o que fazia com que as pessoas desistissem de trabalhar nos seringais. (MILAN, 2011).
\end{abstract}

É possível observar que a extração do látex estava fadada a sua própria decadência, uma vez que não havia planejamento para a sua adequada extração, o que ocasionou tremenda mudança em todo o contexto Amazônico, havendo uma estagnação do ciclo da borracha, por volta de 1930.

Diante desta realidade, as violações de direitos $e$ as precariedades sociais foram determinantes para que a população que

@rquivo Brasileiro de Educação, Belo Horizonte, v. 6, n. 14, mai-ago, 2018. 
dependia da economia da borracha procurasse outros meios de subsistência.

O desdobramento do declínio da borracha culminou na Amazônia paraense $\mathrm{o}$ abandono e a alta criminalidade infanto-juvenil. Neste período ainda, fim do século XIX e início do século XX é importante considerar os debates que ocorriam em nível nacional sobre as legislações de assistência à infância, bem como, a criação de instituições e juizados para estes menores abandonados e delinquentes.

Esses debates culminaram na promulgação do Decreto $n^{\circ} 16.272$, de 20 de Dezembro de 1923, que criava o juízo de menor, no qual o Brasil foi o pioneiro da América Latina e o Decreto de 1927 que promulgava o primeiro código de menores. Pois, se acreditava que através dessas medidas, haveria a possibilidade de se efetivar 0 cuidado e a proteção destes menores, o que de fato não aconteceu.

Logo, quase todo o século XX procurou legislar sobre a vida dos menores abandonados e delinquentes, uma categoria reafirmada principalmente pelo Código de Menores, conhecido como código de Menores Mello Matos, como afirma em seu Art. $1^{\circ}$ "O menor, de um ou outro sexo, abandonado ou delinquente, que tiver menos de 18 annos de idade, será submettido pela autoridade competente ás medidas de assistencia e protecção contidas neste Codigo." (BRASIL, 1927, grafia original), deixando explícito o lugar que estes menores ocupavam na sociedade, geralmente inseridos nas classes excluídas.

Nestas medidas de assistência e proteção, o Pará se integrou. Alguns pesquisadores ${ }^{2}$ que se debruçaram sobre esta temática na Amazônia paraense, apontam para a criação de várias instituições, entre elas, a Colônia Correcional de Menores Abandonados e

\footnotetext{
${ }^{2}$ Ver Melo (2010); Macedo (2014); Alves e Araújo (2016); Quaresma (2017)
}

@rquivo Brasileiro de Educação, Belo Horizonte, v. 6, n. 14, mai-ago, 2018. 
Delinquentes, que posteriormente passou a chamar-se educandário Nogueira de Faria, nome que perdura até hoje.

Sua inauguração se deu em 1933 e seu encerramento em 1967, podendo hoje ser visualizado apenas suas ruínas. Esta inauguração ocorreu no fim da produção da borracha, o que fez com que muitas famílias e suas crianças ficassem desamparadas, fato que aumentou a preocupação da Elite Paraense e do governo. Pois, com o índice alarmante de menores transitando pelas ruas, mendigando e/ou cometendo pequenos crimes, era urgente o controle desta infância desvalida.

A construção do educandário Nogueira de Faria na ilha de Cotijuba $^{3}$ denotava a eficiência do Estado em segregar estes menores que de alguma forma tinham seus vínculos familiares enfraquecidos pelas circunstâncias ora apresentadas.

Porém, com o passar do tempo o educandário que inicialmente foi construido com o objetivo de educar e profissionalizar a infância considerada abandonada e desvalida,passou a ser uma instituição de confinamento não só aos menores, bem como, recebia presos políticos na época da ditadura militar e adultos que cometiam crimes, no qual, todos dividiam os mesmo espaços e assim educandário e presídio coexistiram por anos, o que deu à ilha de Cotijuba a condição de "ilha do diabo" ou a "Alcatraz Amazônica".

\begin{abstract}
A antiga prática de recolher crianças em asilos propiciou a constituição de uma cultura institucional profundamente enraizada nas formas de "assistência ao menor" propostas no Brasil, perdurando até a atualidade. O recolhimento, ou a institucionalização, pressupõe, em primeiro lugar, a segregação do meio social a que pertence o "menor"; o confinamento e a contenção espacial; o controle do tempo; a submissão à autoridade - formas de disciplinamento do interno, sob o
\end{abstract}

\footnotetext{
${ }^{3} \mathrm{~A}$ ilha de Cotijuba é um distrito que pertencente ao município de Belém e a travessia de barco dura aproximadamente 50 minutos.
}

@rquivo Brasileiro de Educação, Belo Horizonte, v. 6, n. 14, mai-ago, 2018. 
manto da prevenção de desvios ou da reeducação dos degenerados. Na medida em que os métodos de atendimento foram sendo aperfeiçoados, as instituições adotavam novas denominações, abandonando o termo asilo, representante de práticas antiquadas, e substituindo-o por outros, como escola de preservação, premonitória, industrial ou de reforma, educandário, instituto. (RIZZINI PILOTTI, 201 1, p.20).

Há tempos as instituições demonstram papeis relevantes na sociedade. Nesta diversidade, há vários tipos de instituições: públicas e privadas, filantrópicas, entre outras. Estas instituições possuem funções sociais e através delas, é possível normatizar e regrar as práticas sociais em determinadas situações.

\begin{abstract}
Quando resenhamos as diferentes instituições de nossa sociedade ocidental, verificamos que algumas são muito mais "fechadas" do que outras. Seu "fechamento" ou seu caráter total é simbolizado pela barreira à relação social com o mundo externo e por proibições à saída que muitas vezes estão incluídas no esquema físico - por exemplo, portas fechadas, paredes altas, arame farpado, fossos, água, florestas ou pântanos. A tais estabelecimentos dou o nome de instituições totais. (GOFFMAN, 2015, p.16).
\end{abstract}

\title{
Instituições
}

Levando em consideração as problematizações sobre instituições à luz de Goffman (2015), podemos considerar o educandário uma instituição total, conforme anunciado por ele?

É possível observar através de suas ruínas que o educandário construído com paredes altas, portas fechadas, água e floresta, não a toa ele se encontra(va) localizado na ilha de Cotijuba, onde o acesso é unicamente fluvial. Goffman, (2015) afirma ainda que existam cinco tipos de instituições, entre estas, existem duas no qual iremos abordar mais a fundo. Uma é a instituição total que é organizada: "para proteger a comunidade contra os perigos intencionais, e o bem-estar das pessoas assim isoladas não constitui o problema imediato: cadeias,

@rquivo Brasileiro de Educação, Belo Horizonte, v. 6, n. 14, mai-ago, 2018. 
penitenciárias, campos de prisioneiros de guerra, campos de concentração". (GOFFMAN, 2015, p.17).

E a outra, são as destinadas com:

Alguma tarefa de trabalho, e que se justificam apenas através de tais fundamentos instrumentais: quartéis, escolas internas, campos de trabalho, colônias e grandes mansões (do ponto de vista dos que vivem nas moradias de empregados). (GOFFMAN, 2015, p.17).

Tais características são pontos de partida para pensarmos na produção do educandário que teceu por décadas um lugar pautado no discurso educativo, forjando práticas disciplinares em nome da disciplina e da ordem social, construindo assim, subjetividades àqueles que ali se encontravam: menores, "vadios" e "abandonados". Muralhas que escondiam, segregavam e condensavam em um único lugar todos os aspectos da vida do menor.

Sabe-se que tal debate possui suas complexidades, pois se trata de refletir sobre práticas institucionais que são atravessadas por um conjunto de dispositivos internos e externos que produzem seus efeitos.

Levando em consideração este dentro e fora da instituição, ou seja, seu intra/extra muros, é importante se fazer uma análise geral das relações de poder que cruzam toda rede institucional.

Um destes dispositivos, segundo Foucault (2011) é o disciplinamento diário que permeia as práticas institucionais, como os horários e a imposição das tarefas, com o objetivo de produzir corpos dóceis e disciplinados.

Pretende-se ampliar o debate das práticas sobre o educandário para além de uma instituição "educacional", pensando de forma macro, tendo-o como efeito de uma prática de múltiplas governamentalidades, descontruindo a noção de instituição como algo dado, naturalizado.

@rquivo Brasileiro de Educação, Belo Horizonte, v. 6, n. 14, mai-ago, 2018. 
Goffman estabeleceu a partir de suas pesquisas considerações sobre o eu civil no dia-a-dia de uma instituição total, pois para ele toda instituição tem tendências de fechamento, como aponta na citação abaixo:

Uma instituição total pode ser definida como um local de residência e trabalho onde grande número de indivíduos com situações semelhantes, separados da sociedade mais ampla por considerável período de tempo, levam uma vida fechada e formalmente administrada. (GOFFMAN, 2015, p. 11).

Sobre o eu civil, Goffman pondera que seu processo de mortificação começa na admissão em dada instituição. Pois, o individuo começará a ser estabelecer, ou seja, a ser instituído de acordo com o que a instituição the oferece de substituição àquilo que Ihe está sendo retirado, seja sua rotina, roupas, alimentos, afetos, sexualidade ou postura corporal. Como aponta Goffman, (2015) "Já sugeri que a autoridade nas instituições totais se dirige para um grande número de itens de conduta - roupa, comportamento, maneiras - que ocorrem constantemente e que constantemente devem ser julgadas" (GOFFMAN, 2015, p.44).

Dentro dessa mortificação do eu civil, muitas vezes é preciso que o indivíduo submetido a uma instituição total abra mão de sua própria vontade para barganhar seus mais simples desejos.

Outra questão que permeia esta mortificação é a minimização do contato/convívio social. Muitas vezes o individuo para manter um mínimo de contato e convívio externo a instituição, precisa passar pela triagem hierárquica da gestão institucional. Geralmente essa triagem se divide em duas categorias: da disciplina e da indisciplina.

Essas duas categorias, na maioria das vezes, se desdobram em critérios que fazem parte das normas da instituição total, limitando-se entre direitos e deveres. Seu cumprimento ou o seu descumprimento

@rquivo Brasileiro de Educação, Belo Horizonte, v. 6, n. 14, mai-ago, 2018. 
certamente acarretará em consequências de ganhos ou perdas ao individuo.

Diferente de Goffman, Foucault não se debruçou sobre a análise das instituições propriamente dita, mas sim das práticas institucionais e das relações de saber-poder-subjetivação.

Neste trabalho sobre as prisões, assim como em outros, o alvo, o ponto de ataque da análise, eram não as "instituições", não as "teorias" ou uma "ideologia", mas as "práticas" - e isto para captar as condições que, em um dado momento, as tornam aceitáveis: a hipótese sendo a de que os tipos de práticas não são apenas comandados pela instituição, prescritos pela ideologia. (FOUCAULT, 2006, p. 337-338).

Os estudos sobre as práticas institucionais por Foucault nos possibilitam pensar na construção histórica das instituições completas e austeras.

Em coleta da história oral com alguns moradores locais sobre o educandário, ouviu-se as barbaries que aconteciam aos menores durante as travessias pelo rio. Muitos nem chegavam a ilha, pois eram eliminados no meio do caminho.

Todo esse processo de institucionalização agenciava múltiplos discursos de caridade e tutela através dos saberes médico, psicológico, jurídico, entre outros.

Uma história de internações para crianças e jovens provenientes das classes sociais mais baixas, caracterizados como abandonados e delinquentes pelo saber filantrópico privado e governamental - elaborado, entre outros, por médicos, juízes, promotores, advogados, psicólogos, padres, pastores, assistentes sociais, sociólogos e economistas - deve ser anotada como parte da história da caridade com os pobres e a intenção de integrá-los à vida normalizada. Mas também deve ser registrada como componente da história contemporânea da crueldade. (PASSETTI, 2013, p. 350).

Por uma ordem social e controle da pobreza, se institucionalizaram esses menores. Michel Foucault nos ajuda a pensar

@rquivo Brasileiro de Educação, Belo Horizonte, v. 6, n. 14, mai-ago, 2018. 
nestes aprimoramentos dos artifícios de governo, investidos na população (biopolítica) e no corpo (disciplina) em uma teia de saberpoder e subjetivação.

O alvo é a infância abandonada e delinquente e para serem capturadas, são usados diversos especialismos. Especialismos que transitam pela saúde, educação, assistência, justiça e etc., que capturam em massa, em nome de um suposto bem estar social. Todavia, esta captura da infância cria mecanismos de poder que regulam a sociedade.

Os discursos são diversos. Eles se deslocam de acordo com cada época em que vivemos. São construídos de acordo com o interesse do momento, constituindo um campo de forças e firmando verdades inventadas, mas que operam como verdades absolutas.

Cabe a nós aceitarmos ou não como naturais, cabe a nós questionarmos e problematizarmos. Um discurso nunca é neutro, ele é recortado, avaliado, ele é escolhido de acordo com o receptor, ou seja, todo discurso tem uma ordem. "Mas, o que há, enfim, de tão perigoso no fato de as pessoas falarem e de seus discursos proliferarem indefinidamente? Onde, afinal, está o perigo?" (FOUCAULT, 2011, p.8)

O discurso por poder ser recortado e selecionado, pode ser usado como instrumento de exclusão ou inclusão, pode qualificar ou desqualificar, pode dar visibilidade ou deixar subliminar e aí está seu perigo.

Somos atravessados diariamente por diferentes discursos que nos trazem efeitos políticos: sobre a infância, sobre a mulher, sobre o negro, os homossexuais, sobre a ciência e os saberes sejam eles médicos, psicológicos, sociológicos, entre tantos outros.

@rquivo Brasileiro de Educação, Belo Horizonte, v. 6, n. 14, mai-ago, 2018. 


\section{Os documentos e as fontes orais}

Para isso, pensando nesses diversos tipos de discursos, sejam eles escritos ou falados, teremos como base documental para esta investigação os documentos custodiados na Biblioteca Arthur Vianna (jornais, boletins informativos e revistas da época). Aqui já elencamos os cinco jornais de maior circulação entre 1933 e 1967 para buscar informações sobre a política de assistência a infância: A Folha do Norte, Diário do Estado, Estado do Pará, O Imparcial e A Província do Pará.

O Centro de Memória da Amazônia (CMA) Universidade Federal do Pará (UFPA) é também um local importante para a reconstrução desta história, pois abriga todos os processos do tribunal de justiça até 1970, bem como, se trará como ancora as falas dos atores remanescentes do educandário.

Pretende-se futuramente investigar o acervo que se encontra no arquivo público do Estado do Pará relacionado à assistência aos menores delinquentes e abandonados, articulando-os com a política institucional engendrada na época.

Até o momento, dentre os jornais escolhidos para a pesquisa documental pouco se encontrou sobre a política de assistência à infância. Ocorreram apenas três notícias que falavam sobre:

a) a inauguração da futura colonia correccional de menores abandonados e delinquentes;

b) o lançamento da pedra do pavilhão destinado à escola desta instituição e

c) sobre o batismo da canoa recém adquirida para o serviço exclusivo da colonia.

@rquivo Brasileiro de Educação, Belo Horizonte, v. 6, n. 14, mai-ago, 2018. 
Nestas notícias, porém, foi possível observar que este jornal era a favor do governo de Magalhães Barata, responsável pela construção da colonia correcional, o que pode ser observado no trecho a seguir:

\begin{abstract}
Iniciativa patriótica e que representa também um desmedido esforço de parte daquelles que a estão realizando, marcará no futuro grandioso de nossa terra um período de administração que não foi somente constructora e fecunda, por que teve, além disso, a preocupação christã de amparar aos pequeninos desherdados da sorte ou do desviados pelos máos caminhos. Ao major Joaquim de Magalhães Barata, interventor federal, a cuja boa vontade e energia se deve a realização de um emprehendimento dessa natureza [...] a essa personalidade cabe os applausos de todos pelo beneficio social que o Pará vae desfructar. (Jornal A folha do Norte, 1933).
\end{abstract}

No Centro de Memória da Amazônia foram consulta dos processos sobre 67 crimes: desobediências, desacatos, lesões corporais, homicídios, roubos, furtos, jogos de azar, capoeiragens e vadiagens, são alguns deles, documentação muito rica para a compreensão da política de assistência a infância no Pará. Porém, dos 776 processos identificados, encontramos apenas cinco que referendavam sobre os menores abandonados e delinquentes, nenhum foi encaminhado ao educandário, embora se encaixassem no perfil social expectável dos institucionalizados: 15 e 17 anos de idade, terem cometido os crimes entre 1934 e 1943, e terem sido julgados e condenados a cumprirem suas penas em prisões juntamente com outros adultos,

As fontes orais são muito importantes, ainda mais para o nosso trabalho, dada a escassez de documentação escrita de que dispomos. Até o momento entrevistamos três agentes ${ }^{4}$ que tiveram envolvimento direto com o educandário: - dois ex-funcionários, uma senhora que tinha a função de passadeira e costureira e um senhor que trabalhou

\footnotetext{
${ }^{4}$ Os três entrevistados foram esclarecidos sobre a pesquisa e consentiram a divulgação de suas entrevistas e imagens, através da assinatura do termo de livre esclarecimento e consentimento.
}

@rquivo Brasileiro de Educação, Belo Horizonte, v. 6, n. 14, mai-ago, 2018. 
como guarda, e um ex-educando, que ao completar a maioridade penal passou a ser funcionário da referida instituição.

$\mathrm{Na}$ fala da primeira entrevistada, é possivel perceber que o educandário era uma instituição onde os menores ficavam recolhidos integralmente, mas que tinham a possibilidade de sair aos finais de semana. Segundo ela, - "quando a criança se apega com a gente, eles ficam amorosos e quando chegava o sábado, eles pediam: peça pro diretor pra passar o dia com a senhora, por que eles passavam o dia todo no colégio, aí eu pedia e o diretor prontamente me dava, eles passavam o sábado e voltava domingo de tarde pra lá".

Interpretando este pequeno trecho, percebe-se que 0 educandário recebia os menores que por algum motivo não tinham a presença de seus familiares/responsáveis, pois passavam os finais de semana na casa da funcionária. Além disso, essas decisões e provavelmente todas as outras tinham que ser hierarquicamente avaliadas pelo diretor da instituição. Mas, não era qualquer menor que tinha esse direito de sair, como a mesma diz, os que ficavam amorosos saíam, logo, os que não eram considerados amorosos, provavelmente permaneciam confinados na instituição.

O segundo entrevistado começou a relatar que "quando os menores infracionavam em Belém vinham pra cá. $O$ educandário era tudo de maior qualidade, era uma escola profissionalizante, que tem gente de profissão honesta até hoje". Indicou ainda que "quando os menores descumpriam alguma regra, sofriam as punições internas da instituição através do trabalho, tinham que limpar, varrer ou ficar privados de sair". Como seria de esperar deste tipo de instituições, o educandário se inseriu na política de assistência à infância como uma instituição que tinha o propósito de educar e disciplinar os menores delinquentes através da profissionalização e das regras estabelecidas.

@rquivo Brasileiro de Educação, Belo Horizonte, v. 6, n. 14, mai-ago, 2018. 
Caso as descumprissem, sofriam sansões como forma de controlar seus comportamentos.

O terceiro e último entrevistado chegou ao educandário com quatorze anos de idade, não por ter cometido alguma infração, mas sim, por ter sido abandonado por seus familiares e maltratado pela segunda família que o acolheu. Aos 18 passou a ser funcionário, no qual exerceu diversas funções como: sentinela, caldeireiro, motorista, chegando a subdiretor, saindo de lá aposentado.

Em seu relato, ora se referia ao educandário como colégio, ora como presídio ou quartel. Explicou que thes eram ofertados oficinas profissionalizantes como panificação, alfaiataria, marcenaria, entre outras.

Disse ainda que "internamente ao entrar no educandário, todos os "menores" tinham que raspar os cabelos e a se submeter a uma rotina que começava às 5 horas da manhã, onde eram acordados pelo tocar do corneteiro, em seguida marchavam em fila, uniformizados, tendo que fazer continências aos funcionários e cantar o hino nacional do Brasil e o hino da ilha de Cotijuba, tinham ainda que pela manhã, capinar, roçar, tirar o lixo e etc".

Esses recursos utilizados de forma arbitrária pelos funcionários da instituição e as tarefas diárias, geriam o tempo e o espaço, servindo para docilizar os menores.

O que observamos em relação à disciplina é que ela controla em nome de um caráter pedagógico como um exercício, pois Foucault em Vigiar e Punir fala sobre as disciplinas nas prisões. A disciplina é a própria (micro) física do poder, instituída para controle e sujeição do corpo, com o objetivo de tornar o indivíduo dócil e útil: uma política de coerção para domínio do corpo alheio, ensinado a fazer o que queremos e a operar como queremos. O objetivo de produzir corpos

@rquivo Brasileiro de Educação, Belo Horizonte, v. 6, n. 14, mai-ago, 2018. 
dóceis e úteis é obtido por uma dissociação entre corpo individual, como capacidade produtiva, e vontade pessoal, como poder do sujeito sobre a energia do corpo.

Do ponto de vista da Psicologia, considera-se que todo sujeito é um ser biopsicossocial, sendo assim, é de suma importância considerar a bioética na interface das relações sociais e dos agenciamentos propostos no trato com a infância.

Questões como a bioética nos trazem reflexões desafiantes perante as decisões que devem ser tomadas não só no âmbito da saúde como também da assistência, pois em ambas se decide sobre a vida. Bem maior que um sujeito pode possuir. Mas, como essas decisões devem ser tomadas? Neste caso, "a Bioética constitui o novo semblante da ética cientifica". (CLOTET, 2003)

Em pesquisas em diversas fontes, uma delas sendo a base de periódicos da CAPES5, não há escritos sobre a bioética e a Psicologia Social. Encontra-se em grandes escalas a bioética relacionada à saúde. Mas, considerando que toda Psicologia é Psicologia Social, pois o objeto de estudo dessa ciência é o sujeito, por que não relacionar a bioética para além dos muros do que se considera saúde?

Este artigo propõe esta interface, uma vez que:

\begin{abstract}
A Bioética precisa, portanto, de um paradigma de referência antropológico-moral que, implicitamente, já foi colocado: o valor supremo da pessoa, da sua vida, liberdade e autonomia. Esse princípio, porém, às vezes parece conflitar com aquele outro, relativo à qualidade de vida digna que merecem ter 0 homem e a mulher. Nem sempre os dois princípios se amoldam perfeitamente sem conflitos, no mesmo caso. Sabemos por própria experiência que, em determinadas circunstâncias, não é fácil tomar uma decisão. Constitui uma tarefa da Bioética fornecer os meios para fazer uma opção racional de caráter moral referente à vida, saúde ou morte, em situações especiais, reconhecendo que esta determinação terá que ser dialogada, compartilhada e decidida entre pessoas com valores morais
\end{abstract}

\footnotetext{
${ }^{5}$ Coordenação de Aperfeiçoamento de Pessoal de Nível Superior
}

@rquivo Brasileiro de Educação, Belo Horizonte, v. 6, n. 14, mai-ago, 2018. 
diferentes. Para um melhor entendimento das exigências e dificuldades da Bioética, esta deve ser compreendida, no momento atual da nossa cultura e civilização, dentro da "linguagem dos direitos" (22). O movimento em favor dos direitos humanos promoveu o movimento dos direitos do enfermo (A patient's bill of rights, Hospitals 1973: 47). Fora desse contexto resulta difícil entender, explicitar e justificar a Bioética. (CLOTET, 2003 p.4).

Pensando na governamentalidade desses sujeitos, Foucault em seu livro História da Sexualidade I: a vontade de saber, no quinto capitulo escreve sobre o direito de vida e o direito de morte, ou melhor, dizendo, o fazer morrer ou deixar viver, cita que: "O poder era, antes de tudo, nesse tipo de sociedade, direito de apreensão das coisas, do tempo, dos corpos e, finalmente, da vida; culminava com o privilégio de se apoderar da vida para suprimi-la". (FOUCAULT, 1999, p. 128).

Várias formas de se deixar viver surgem e várias formas de se fazer morrer também, não a morte corporal em si, mas a morte ou a vida da alma. Deixa-se morrer quando se encarcera e não se garante os direitos básicos da vida, faz-se viver no cuidar, na garantia dos direitos à vida, no direito à saúde individual e coletiva, tendo condições existenciais com equidade para todos.

Por fim, ainda não trago conclusões, apenas algumas ideias gerais sobre a política de assistência aos menores no Pará, concretamente, sobre o educandário Nogueira de Faria, fundado na ilha de Cotijuba sob a governança do intendente major Magalhães Barata. Tendo acolhido menores delinquentes e abandonados, teve como objetivo gerir a pobreza, mas não acabar com ela, como é possível constatar nas falas dos entrevistados.

\section{REFERÊNCIAS}

BRASIL. Decreto n 16.272, de 20 de Dezembro de 1923. Aprova o regulamento da assistência e proteção aos menores abandonados e

@rquivo Brasileiro de Educação, Belo Horizonte, v. 6, n. 14, mai-ago, 2018. 
delinquentes. Diário Oficial da União, Rio de Janeiro, 21 dez. 1923.

Disponível em:

http://www2.camara.leg.br/legin/fed/decret/1920-1929/decreto-1627220-dezembro-1923-517646-publicacaooriginal-1-pe.html. Acesso em: 23 jun. 2017.

BRASIL. Decreto no 17.943-A, de 12 de outubro de 1927. Consolida as leis de assistência e proteção a menores. Coleção de Leis do Brasil, Rio de Janeiro, 31 dez. 1927. Disponível em:

http://www2.camara.leg.br/legin/fed/decret/1920-1929/decreto-17943a-12-outubro-1927-501820-publicacaooriginal-1-pe.html. Acesso em: 23 jun. 2017.

CLOTET, Joaquim. Por que Bioética? In: CLOTET, Joaquim. Bioética: uma aproximação. Porto Alegre, RS: Edipucrs, 2003. Disponível em:

http://www.pucrs.br/edipucrs/digitalizacao/irmaosmaristas/bioetica.pdf. Acesso em: 07 mar. 2019.

FOUCAULT, Michel. História da sexualidade I: a vontade de saber. 13. ed. Tradução de Maria Tereza da Costa Albuquerque e J. A. Guilhon Albuquerque. Rio de Janeiro: Graal, 1999.

FOUCAULT, Michel. A ordem do discurso. 21. ed. São Paulo: Edições Loyola, 2011.

FOUCAULT, Michel. O poder psiquiátrico. São Paulo: Martins Fontes, 2006.

GOFFMAN, Erving. Manicômios, prisões e conventos. Tradução de Dante Moreira Leite. São Paulo: Perspectiva, 2015. (Debates; 91).

GUILLEN, Isabel Cristina Martins. Cidadania e exclusão social: a história dos soldados da borracha em questão. Revista Trajetos, v. 1, n. 2, p. 110, 2002.

KRAMER, Sônia. A política do pré-escolar no Brasil: a arte do disfarce. São Paulo: Cortez, 2001.

MILAN, Pollianna. Tráfico de semente fez ruir ciclo da borracha. Gazeta do Povo, Curitiba, 16 set. 2001. Disponível em:

http://www.gazetadopovo.com.br/vida-e-cidadania/trafico-desemente-fez-ruir-ciclo-da-borracha-caitl4phpdvł4f5zzipbt6gr2. Acesso em: 21 jun. 2017.

@rquivo Brasileiro de Educação, Belo Horizonte, v. 6, n. 14, mai-ago, 2018. 
MITCHELL, Angus. Roger Casement no Brasil: a borracha, a Amazôniae o mundo atlântico, 1884-1916. Tradução de Mariana Boufarine e organização de Laura P. Z. Izarra. São Paulo: W.B yeats Chair of Irish Studies; Humanitas, 2011.

PASSETTI, Edson. Crianças carentes e políticas públicas. In: PRIORE, Mary del (org.). História da criança no Brasil. São Paulo: Contexto, 2013. p. 347-375.

RIZZINI, Irene; PILOTTI, Francisco. A arte de governar crianças: a história das políticas sociais, da legislação e da assistência à infância no Brasil. 3. ed. São Paulo: Cortez, 2011.

@rquivo Brasileiro de Educação, Belo Horizonte, v. 6, n. 14, mai-ago, 2018. 